\title{
Scheduling Chemotherapy: Catch 22 between Cell Kill and Resistance Evolution
}

\author{
SHEA N. GARDNER* \\ NERC Centre for Population Biology, Imperial College at Silwood Park, Ascot, Berkshire SL5 7PY UK
}

(Received 1 June 1999; In final form 6 October 1999)

\begin{abstract}
Dose response curves show that prolonged drug exposure at a low concentration may kill more cells than short exposures at higher drug concentrations, particularly for cell cycle phase specific drugs. Applying drugs at low concentrations for prolonged periods, however, allows cells with partial resistance to evolve higher levels of resistance through stepwise processes such as gene amplification. Models are developed for cell cycle specific (CS) and cell cycle nonspecific (CNS) drugs to identify the schedule of drug application that balances this tradeoff.

The models predict that a CS drug may be applied most effectively by splitting the cumulative dose into many $(>40)$ fractions applied by long-term chemotherapy, while CNS drugs may be better applied in fewer than 10 fractions applied over a shorter term. The model suggests that administering each fraction by continuous infusion may be more effective than giving the drug as a bolus, whether the drug is CS or CNS. In addition, tumors with a low growth fraction or slow rate of cell division are predicted to be controlled more easily with CNS drugs, while those with a high proliferative fraction or fast cell division rate may respond better to CS drugs.
\end{abstract}

Keywords: Continuous infusion, cell cycle phase-specific, chemotherapy, gene amplification, resistance evolution, drug kinetics

\section{INTRODUCTION}

For the majority of cancer chemotherapeutics, the optimal schedule of administration has not been established (Donehower 1990). The reasons that the effectiveness of chemotherapy depends on drug scheduling are myriad and complex. Two of the most obvious are that selection for drug resistance depends on the timing by which a drug is applied and that some drugs display contrasting cytotoxicities for cells in different parts of the cell cycle. Skipper et al. $(1967,1979)$ and Bruce et al. (1966) showed that the chemotherapy dose response curve resulting from a single dose (applied as a spike) of cell cycle specific drugs (CS drugs) levels off with increasing doses (reviewed in vanPutten 1974, Steel 1977). This tapering dose response curve contrasts with the log linear increase in cell kill with increasing dose for cycle non-specific drugs (CNS drugs). The reason for the difference between CS

${ }^{*}$ Current Address: Biology and Biotechnology Research Program, Lawrence Livermore National Laboratory, P.O. Box 808, L-452, Livermore, CA 94551-0452. Fax: (925) 422-2282; E-mail: gardner26@llnl.gov 
and CNS drugs is that, for CS drugs, only a fraction of the total cells are dividing, and thus susceptible, at any time. Since drug half life is usually shorter than the intermitotic time, the dose falls exponentially before all of the cells enter mitosis, putting an upper limit on the cell kill for a given dose. Evidence for this reasoning shows that the leveling of the dose response curve occurs after three to four orders of magnitude greater cell kill in a cancer with a high proliferative fraction compared to a cancer with a low proliferative fraction, since more dividing cells result in greater drug exposure (Bruce et al. 1966).

Skipper et al. (1967) demonstrated that prolonging drug exposure by continuous infusion (CI) for a period of at least half the cell cycle time resulted in longer survival of mice with leukemia L1210 than administering a spiked dose either once (at a high concentration) or daily (at a low concentration). This result implies greater tumor cell kill from CI than from a spiked dose, since more dividing cells are exposed to the drug at relatively high concentrations.

Many studies, however, suggest that drug resistance evolves sooner at lower dose intensities, and conclude that chemotherapy should be given at the maximum feasible concentration from the beginning of treatment (Schimke 1984, Hokanson et al. 1986, Coldman and Goldie 1987a, Panetta 1998). Resistance can often be overcome by dose intensification (Tsuruo and Fidler 1981, Griswold et al. 1987). There is evidence that the steep increase in cell kill with increasing dose of most chemotherapeutic drugs means there are substantial benefits of using higher doses rather than prolonged exposure to lower doses (Frei and Canellos 1980, Schimke 1984, Rath et al. 1984, Bezwoda et al. 1995, Hryniuk 1995). Thus, one faces a Catch 22 of whether to apply a given total dose of a CS drug at low concentrations for an extended period, to reach more cells as they divide, or to apply the drug as a few, highly concentrated dose spikes, to delay the evolution of resistance. This double bind situation may not plague chemotherapy with CNS drugs: steep dose response curves and the potential to delay resistance evolution both seem to argue for high-concentration dose spikes rather than prolonged CI. Such Catch 22 situations are not exclusive to cancer chemotherapy; debates over resistance evolution and pest control resulting from high versus low pesticide or antibiotic doses are found in agricultural and infectious disease research as well (Gressel et al. 1996, Gardner et al. 1998).

The drug methotrexate (MTX) is a good example of the Catch 22 described above. It is a CS drug frequently used in cancer chemotherapy that is an antimetabolite and a folic acid analogue. One of the most common and important mechanisms for the evolution of MTX resistance is gene amplfication of the dihydrofolate reductase (DHFR) gene by stepwise selection (Schimke et al. 1985). Resistance results from sufficient overproduction of DHFR to overcome enzyme inhibition. Experimental data using MTX illustrate the afforementioned double bind of whether to apply the dose by prolonged $\mathrm{CI}$ or by rapid injection: on the one hand, dose response curves show that increasing the duration of drug exposure has a greater cytotoxic effect than increasing the dose (Eichholtz and Trott 1980, Keefe et al. 1982). These authors conclude that "protracted infusions of lower doses of MTX would be equally as useful as or more useful than short-term highdose infusions," (p.1641, Keefe et al. 1982). In other experiments, however, cells were exposed either to a high concentration of MTX from the start, or were exposed to gradually increasing concentrations by stepwise dose escalation up to the same high dose as in the single-step procedure (Rath et al. 1984). Under the step-wise selection protocol, resistance evolved to the high dose after only 6.5 days, and the DHFR genes had undergone 6-fold amplification. Under the single-step selection procedure, resistance took 45 days to evolve, and resistant variants did not contain amplified DHFR genes. Thus, low drug concentrations facilitated the evolution of resistance. A number of clinical studies have shown three- to sixfold amplification of DHFR genes in patients resistant to MTX, with cancers ranging from leukemia (Horns et al. 1984, Cardman et al. 1984), to lung cancer (Curt et al. 1983) and ovarian cancer (Trent et al. 1984). 
Resistance to a number of other drugs such as the vinca alkaloids, vinblastine and vincristine, as well as cisplatin and 5-fluorouracil, may occur through gene amplification (Rath et al. 1984, Harnevo and Agur 1992). The multi-drug-resistance (MDR) gene, one of the main problems in chemotherapy, also evolves by gene amplification (Schoenlein 1993, Kellen 1994, Bodey et al. 1997). Hence, the tradeoff between prolonged, low-concentration CI to increase cell kill and short, high concentration bolus injections to preclude resistance evolution is likely to apply for other drugs in addition to MTX. Moreover, the logic may be relevant to antibiotic and other therapy as well as to cancer chemotherapy; Escherichia coli and Leishmania tropica have both been shown to evolve drug resistance by gene amplification (Schimke 1984), and insecticide resistance may also evolve through gene amplification (Devonshire and Field 1991).

This paper presents a model of tumor growth and resistance evolution for different schedules of treatment using either a CS or a CNS drug. The cumulative amount of drug administered may be split into a number of fractions separated by twoweek intervals, and each fraction may be given by $\mathrm{CI}$ of short or long duration. Chemotherapy is considered long term if the dose is split into many fractions, and short term if it is divided into relatively few fractions. The model is used to mathematically assess the hypothesis that CS drugs reduce tumors to smaller sizes with a specified cumulative drug dose if that dose is given by long term chemotherapy applied by CI, while CNS drugs minimize tumor size if they are applied by shorter term chemotherapy administered by high-concentration bolus. Using a system of differential equations, the model describes a population of tumor cells in which mutation and selection result in clonally heterogeneous levels of drug resistance. Resistance may evolve in a stepwise fashion as cells accumulate many mutations of small effect, or as a single mutation of large effect occurring in one cell division. Cells may transfer between a resting $(\mathrm{G} 0)$ or a proliferating state. Only a fraction of cells in the proliferating state are vulnerable to the CS drug at any given time, corresponding to the observation that many drugs can kill cells in one but not all phases of mitosis. The CNS drug, in contrast, can kill cells in the resting and the proliferating states. The model calculates the duration of CI and the number of dose fractions that minimize tumor size. The results depend not only on whether the drug is phase-specific or phase-nonspecific, but also on the dose applied, the fraction of proliferating cells, and the cell cycle time of proliferating cells.

For clarity in interpreting the results, certain simplifying assumptions are made. First, dynamics are deterministic so that the mean behavior of the population is predicted but fluctuations around the mean are not. Second, only a single drug is applied to any given tumor, although in another analysis the application of multiple drugs simultaneously will be examined (Gardner, in prep.). In addition, host toxicity is not modeled explicitly, but is assumed to depend on the area under the drug concentration $x$ time curve (AUC), as is the case for many cancer chemotherapeutics (Evans 1988, Rushing et al. 1994, Sasaki et al. 1995, Canal et al. 1996, Joel et al. 1996). Therefore, as shown elsewhere (Gardner, submitted), the AUC depends on the total dose administered but not on the schedule by which it is given, assuming the drug concentration decays exponentially with a half life that does not change if it is given by different schedules. While the drug half life in the host may not be the same for schedules as different as a highly concentrated dose spike versus a very low-concentration, prolonged CI (Sobrero et al. 1997), it is likely to be similar for less dramatic differences in scheduling (Comandone et al. 1998). Thus, for a given dose that is known not to be overly toxic, the model predicts the schedule to minimize tumor size and/or maximize the time to host death. It is assumed that the total dose and drug concentration at any point in time is that which reaches the tissue or organ containing the tumor. Finally, there is no spatial component to the model, and it is assumed that the drug is evenly distributed throughout the tumor. Although for a large solid tumor with poor blood perfusion this is an inappropriate assumption, it may be a reasonable assumption for 
a blood tumor like leukemia, a highly vascularized solid tumor, or for cancer in which there are many, small micrometastases.

The questions of how resistance evolution interacts with factors such as the rate of cell proliferation and the application schedule, and how this interaction differs for drugs with contrasting effects on cell kinetics, is what is attempted here. While a number of excellent chemotherapy resistance models have been developed, the questions addressed by the model proposed here differ, as do some of the assumptions, from those of other studies. Most theoretical studies model one or the other of CS drugs (Hokanson et al. 1986, Birkhead et al. 1987) or CNS drugs (Coldman and Goldie 1987a, Harnevo and Agur 1991, Murray 1995, Panetta 1998), but do not juxtapose how the two kinetically disparate types of drugs select for resistance. One study (Duk and Nickolls 1987) does so, but assumes that all mortality is drug-induced. This assumption affects the rate of evolution of resistance (Coldman and Goldie 1987b) and is at odds with empirical findings of high rates of natural apoptosis and cell turnover (Steel 1977, Meyer 1989, Watson 1991, Kerbel 1995). Moreover, most resistance models generally assume that drugs are applied as a series of dose spikes, but do not compare bolus versus CI therapy (but see Murray 1995, Duk and Nickolls 1987), or short duration versus long duration CI. Finally, in contrast to models which assume that cells are either fully susceptible or fully resistant (but see Harnevo and Agur 1991, Michelson 1993 for exceptions), the model presented here incorporates the possibility that drug dose affects both the fraction of susceptible cells that are killed as well as drug susceptibility itself, since dose response curves for different clones within a tumor depend on the level of resistance possessed by that clonal lineage.

Although the model developed here clearly has shortcomings, such as the simplifying assumptions described above, it is intended to be a logical tool to help make sense of the conflicting arguments and empirical results regarding bolus versus $\mathrm{CI}$ scheduling of a given, cumulative drug dose, like the debate discussed above for MTX. Specifically, this model is aimed to shed light on the following questions: Is it better to administer a drug as many or as a few fractions, and is it better to give the drug rapidly or by prolonged CI at each fraction? Does the answer depend on whether the drug is CS or CNS? In addition, these analyses address the question of whether a CS or a CNS drug may be more effective against a tumor with a fast versus a slow cell cycle time of proliferating cells, or a high versus a low proliferative fraction. It is hoped that experimental tests will be performed to assess the validity of the predictions from this model for drugs in which resistance may evolve in a stepwise manner.

\section{METHODS: THE MODEL}

In this section, equations are presented to model tumor growth and resistance evolution in the presence of a CS or CNS drug. The tumor is subdivided into proliferating and resting cells in the G0 state (Figure 1). Cells may transfer between these two states. As modeled elsewhere (Birkhead et al. 1987), cells in the proliferating compartment divide exponentially at a rate $b$. Cells in the G0 state may die by necrosis at a rate $v$, and those in the proliferating state may die by apoptosis at a rate $a$. The rate of apoptotic cell death in the absence of the drug is assumed to be $85 \%$ of the rate of cell division of proliferating cells $(a=0.85 b)$, based on empirical estimates (Meyer 1989, Watson 1991). CS drugs generally can kill cells only while they are in a specific phase of the proliferative state, so only a fraction $f$ of proliferating cells are vulnerable to the drug. A CNS drug can kill cells in both the proliferating and the resting states. Cell kill is assumed to be negative exponential with drug dose (Skipper et al. 1967, Steel 1977).

Within both the proliferating and the resting states, a tumor is composed of a number of clonal cell lines, each with a level of resistance $r$ (Figure 2). The probability of a small mutation that increases the level of resistance an incremental amount is assumed to be $\mu_{\mathrm{s}}=10^{-4}$, based on 


\section{Dynamics of Tumor Growth and Drug Effects}

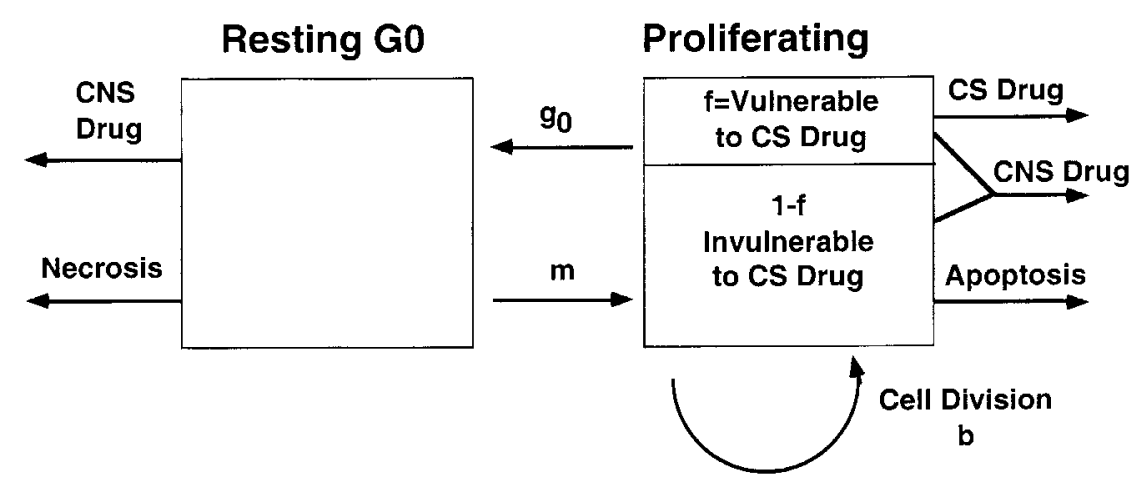

FIGURE 1 Diagram of the model. Cells in the proliferating state divide at a rate $b$, die via apoptosis at a rate $a$, and may transfer to the resting state at a rate $g_{0}$. Cells in the resting state die via necrosis at a rate $v$ or transfer back to the proliferating state at a rate $m$. CNS drugs can kill cells in either the resting or the proliferating state, while CS drugs can kill only a fraction $f$ of proliferating cells at any one time.

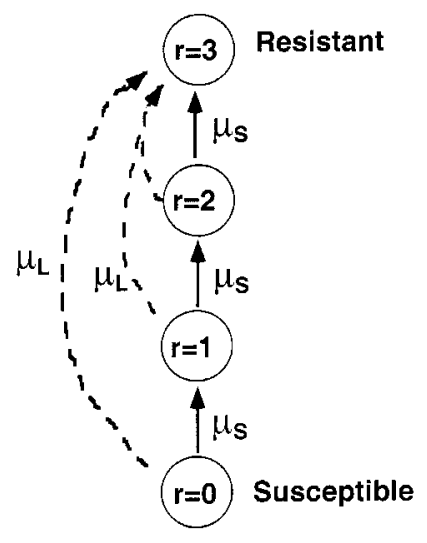

FIGURE 2 Diagram of resistance evolution. Cells may acquire a small mutation increasing the level $r$ of resistance by one, with probability $\mu_{\mathrm{s}}$, or they may sustain a large mutation that increases $r$ up to the maximum resistance in one cell generation. with probability $\mu_{\mathbf{L}}$

empirical estimates of the rate of gene amplification (Schimke 1984). The probability of a large mutation $\mu_{\mathrm{L}}$ that confers full resistance to a drug in a single cell generation is assumed to be either $10^{-6}$ or $10^{-10}$. The greater probability $10^{-6}$ is chosen based on estimates of the average mutation rate per protein observed in human systems. The lower value $10^{-10}$ was selected based on estimates of the frequency of single base-pair changes in human DNA, and is an appropriate choice for the value of $\mu_{\mathrm{L}}$ if resistance requires specific mutations at particular locations in the DNA, as seems to be the case (Goldie and Coldman 1998).

Resistance $r$ is an integer that ranges from zero for susceptible cells to $r_{\max }=3$ for fully resistant cells. The value of $r-r_{\max }$ represents the slope of the log-linear dose response curve of cell survival for cells in the susceptible part of the cell cycle, so that if $r=r_{\max }$ the cell does not suffer reduced survival as a result of drug exposure. Four states for $r$ seemed like a reasonable balance between a two-state system if resistance were all-or-nothing (i.e. single gene of large effect, not gene amplification) and a much larger system, for example, with ten states, in which nine gene amplifying mutations would be necessary for complete resistance. Such a large number of steps would require many cell divisions before substantial levels of resistance evolved by gene amplification, resulting in model predictions that one would always observe resistant tumors to arise by mutations of large effect $\left(\mu_{\mathrm{L}}\right)$ rather than by gene amplification $\left(\mu_{\mathrm{S}}\right)$. In fact, with $\mu_{\mathrm{L}}=10^{-10}$ and $r_{\max }=10$ the model makes the unrealistic prediction that moderate levels of resistance will not evolve before the tumor is detected at $10^{9}$ cells, and, therefore, that cure may be easily achieved. In summary, $r_{\max }=3$ seems to be a reasonable choice. 


\section{Before Chemotherapy Begins}

The number of cells at time $t$ in state $s$ and with resistance $r$ is given by $N(r, s, t)$, where $s=G 0$ if cells are in the resting state and $s=P$ if cells are in the proliferating state. In the absence of the drug, the rate of change of the number of cells in the resting state is

$$
\begin{aligned}
\frac{d N(r, G 0, t)}{d t}= & -m N(r, G 0, t)+g_{0} N(r, P, t) \\
& -v N(r, G 0, t)
\end{aligned}
$$

for $r=0,1,2,3$, where $m$ is the rate of transition from the resting to the proliferating state, $g_{0}$ is the rate of transition from the proliferating to the resting state, and $v$ is the rate of necrosis. The rate of change in the number of proliferating cells for which $r=0,1,2$ is

$$
\begin{aligned}
\frac{d N(r, P, t)}{d t}= & N(r, P, t) b\left(1-\mu_{S}-\mu_{L}\right) \\
& +N(r-1, P, t) b \mu_{S}\left(1-\mu_{L}\right) \\
& -a N(r, P, t)-g_{0} N(r, P, t) \\
& +m N(r, G 0, t)
\end{aligned}
$$

where the first term on the right represents cells which divide and do not incur any mutations that increase resistance, the second term represents cells which divide and undergo a small mutation that increases $r$ by one, the third term represents apoptotic cell death, the fourth term describes cells that enter the resting state, and the fifth term indicates cells that reenter the proliferating from the resting state. If $r=r_{\max }=3$ then the change in the number of proliferating cells is

$$
\begin{aligned}
\frac{d N\left(r_{\max }, P, t\right)}{d t}= & b N\left(r_{\max }, P, t\right) \\
& +N\left(r_{\max }-1, P, t\right) b \mu_{S}\left(1-\mu_{L}\right) \\
& +\sum_{i=1}^{r_{\max }-1} N(i, P, t) b \mu_{L} \\
& -a N\left(r_{\max }, P, t\right)-g_{0} N\left(r_{\max }, P, t\right) \\
& +m N\left(r_{\max }, G 0, t\right)
\end{aligned}
$$

The third, summation term in Equation 3 that is additional to the terms described Equation 2 represents divisions in which large mutations generate fully resistant cells. In the absence of the drug, resistance can evolve, although it confers no selective advantage.

\section{Chemotherapy with a CS Drug}

Once the tumor is detected at $t=t_{\text {detect }}$ when it reaches $10^{9}$ cells (approximately a cubic centimeter), chemotherapy begins. The drug concentration at time $t$ is given by $y(t)$. The probability that a cell in the proliferating state with resistance $r$ survives a CS drug at concentration $x$ is

$$
\operatorname{Surv}(r, f, x)=1-f+f \exp \left[-x\left(r_{\max }-r\right)\right]
$$

where $1-f$ is the fraction of cells that are invulnerable to the drug because of their position in the mitotic cycle, and $f \exp \left[-x\left(r_{\max }-r\right)\right]$ is the probability of survival of vulnerable cells exposed to a concentration of $x$ times the vulnerable fraction $f$. The $\log$ survival of vulnerable cells versus drug concentration is a line, as observed empirically (Skipper et al. 1967), with slope $r-r_{\max }$.

Thus, for CS drugs with $r=0,1,2$

$$
\begin{aligned}
\frac{d N(r, P, t)}{d t}= & b N(r, P, t)\left[1-\mu_{S}-\mu_{L}\right] \operatorname{Surv}(r, f, y(t)) \\
& +b N(r-1, P, t) \mu_{S}\left[1-\mu_{L}\right] \\
& \times \operatorname{Surv}(r-1, f, y(t)) \\
& -a N(r, P, t)-g_{0} N(r, P, t) \\
& +m N(r, G 0, t)
\end{aligned}
$$

The first term on the right models cells which divide, survive division, and do not undergo resistant mutations. The second term represents cells which divide, survive division, and do undergo a small resistant mutation. Drug-induced kill and cell division are linked because they always appear as the product $b \operatorname{Surv}(r, f, y(t))$. Thus, surviving the CS drug is more important if $b$ is large than if $b$ is small. As before, the last three terms describe apoptosis and transitions between the proliferating and the resting 
states. If $r=r_{\max }=3$ there is an additional term for the probability of large resistance mutations, so

$$
\begin{aligned}
\frac{d N\left(r_{\max }, P, t\right)}{d t}= & b N\left(r_{\max }, P, t\right) \\
& +b N\left(r_{\max }-1, P, t\right) \mu_{S}\left(1-\mu_{L}\right) \\
& \times \operatorname{Surv}(r-1, f, y(t)) \\
& +\sum_{i=1}^{r_{\text {max }}-1} b N(i, P, t) \\
& \times \mu_{L} \operatorname{Surv}(i, f, y(t)) \\
& -a N\left(r_{\max }, P, t\right)-g_{0} N\left(r_{\max }, P, t\right) \\
& +m N\left(r_{\max }, G 0, t\right)
\end{aligned}
$$

Treatment with a CS drug does not affect the cells in G0, so the rate of change of the resting subpopulation still follows Equation 1. The Equations 5-6 are similar to the equations presented by Norton and Simon (1977, 1986) for tumor growth in the presence of a CS drug. Their model, however, did not include the evolution of resistance, cells in the resting state $\mathrm{GO}$, and cells in the proliferating state which may nonetheless be invulnerable to the drug (e.g. cells in G1 phase are invulnerable to an S-phase specific drug such as MTX).

\section{Chemotherapy with a CNS Drug}

For CNS drugs, drug-induced mortality affects all cells regardless of their mitotic status. Thus, the probability that a cell in either G0 or $\mathrm{P}$ survives a CNS drug of concentration $x$ is $\operatorname{Surv}(r, f, x)$, with $f=1$, and kill occurs independently of the rate of cell proliferation. So the rate of change in the number of tumor cells for $r=0,1,2$ is

$$
\begin{aligned}
\frac{d N(r, P, t)}{d t}= & b N(r, P, t)\left(1-\mu_{S}-\mu_{L}\right) \\
& +b N(r-1, P, t) \mu_{S}\left(1-\mu_{L}\right) \\
& -N(r, P, t)[1-\operatorname{Surv}(r, 1, y(t))] \\
& -a N(c, t)-g_{0} N(r, P, t) \\
& +m N(r, G 0, t)
\end{aligned}
$$

and for $r=r_{\max }$

$$
\begin{aligned}
\frac{d N\left(r_{\max }, P, t\right)}{d t}= & b N\left(r_{\max }, P, t\right) \\
& +N\left(r_{\max }-1, P, t\right) b \mu_{S}\left(1-\mu_{L}\right) \\
& +\sum_{i=1}^{r_{\max }-1} N(i, P, t) b \mu_{L} \\
& -N\left(r_{\max }, P, t\right)[1-S u r v(r, 1, y(t))] \\
& -a N\left(r_{\max }, P, t\right)-g_{0} N\left(r_{\max }, P, t\right) \\
& +m N\left(r_{\max }, G 0, t\right)
\end{aligned}
$$

In contrast to Equations 5-6 for the CS drug, Equations 7-8 for the CNS drug include druginduced cell kill independently of cell division. The CNS drug may also kill cells in G0, so (for $r=$ $0,1,2,3)$

$$
\begin{aligned}
\frac{d N(r, G 0, t)}{d t}= & -m N(r, G 0, t)+g_{0} N(r, P, t) \\
& -v N(r, G 0, t) \\
& -N(r, G 0, t) \\
& \times[1-\operatorname{Surv}(r, 1, y(t))]
\end{aligned}
$$

Solutions were computed numerically using fourth-order Runge-Kutta, beginning with a susceptible tumor of 100 cells $(N(0, P, 0)=100)$. If the number of cells in a subpopulation was less than one then the size of that subpopulation was set to zero.

In the results presented, it was assumed that $m=$ $0.05, v=0.01, g_{0}=0.1$, and $b=0.5$ unless specified otherwise. These values produced results that were similar to empirical data: a growth fraction (fraction of proliferating cells) of $52 \%$ at the time of tumor detection, and a cell cycle time of 33 hours (Steel 1977). Sensitivity analyses were used to examine the effects of the scheduling of chemotherapy on the minimum tumor size for tumors with transition rates $100 \%$ higher or $90 \%$ lower than the baseline values specified above (except for $b$, which took on a minimum value of 0.2 , since lower values did not result in tumor growth).

The above assumptions about the transition rates in tumors describe a number of situations in which tumor growth is exponential, at least over an observed range (e.g. Steel, 1977, pp. 42-43). 
However, in some situations a saturating curve such as Gompertzian growth provides a better fit to data (Marusic et al. 1994). Gyllenburg and Web (1989) showed that Gompertzian growth may occur if the transition rate from the proliferating to the resting state is logarithmic with total tumor size. Thus, we examined model predictions for a tumor in which the growth rate decreases with tumor size. The constant transition rates $m, v$, and $g_{0}$ were replaced with functions that depended on tumor size $N: m=$ $0.23-0.006 \log (N), v=0.0003 \log (N)$, and $g_{0}=$ $0.01 \log (N)$, chosen by trial and error to predict a reasonable growth fraction $(30 \%)$ and ratio of necrotic cells to $(G 0+P)$ cells $(15 \%)$ at the time the tumor is detected (Steel, 1977, Gasparini et al. 1991). The predictions about treatment schedules using the size-dependent transition rates, resulting in saturating tumor growth, were qualitatively and quantitatively similar to predictions for the case of exponential tumor growth, modeled using the constant transition probabilities. In the interest of space, only results assuming exponential tumor growth are presented. This is a common simplifying assumption in models of cancer growth and resistance evolution (Birkhead et al. 1987, Duc and Nickolls 1987, Murray 1995, Panetta 1998).

\section{Drug Concentration}

It is assumed that one applies a total (cumulative) drug dose of $D \mathrm{mg} \mathrm{m}^{-2}$, split into $z$ fractions, each given at an interval of $q$, which is assumed to be 14 days. Each fraction is given by infusion for a duration of $u$ days at a rate of $D /(z u) \mathrm{mg} \mathrm{m}^{-2}$ day. Then, for $t \leq q$ the drug concentration in the body changes at the rate of

$$
\frac{d(y(t \leq q))}{d t}= \begin{cases}D /(z u)-\lambda y(t) & \text { for } t \leq u \\ -\lambda y(t) & \text { for } t>u\end{cases}
$$

Integrating and setting $y(0)=0$ yields the drug concentration at time $t \leq q$

$$
y(t \leq q)= \begin{cases}\frac{D}{\lambda z u}\left(1-\mathrm{e}^{-\lambda \mathrm{t}}\right) & \text { for } t \leq u \\ \frac{D}{\lambda z u} \mathrm{e}^{-\lambda \mathrm{t}}\left(e^{\lambda u}-1\right) & \text { for } t>u\end{cases}
$$

For the $z$ th fraction, $y(t>z q)$ was set equal to $y(t-$ $[z-1] q)$ calculated with Equations $10-11$, so that drug concentration during each fraction followed the same pattern as in the first fraction.

\section{RESULTS}

When CS drug delivery is too fast (Figure $3 \mathrm{~A}$ ), not all the cells divide during the period of infusion, and thus some cells escape drug exposure and survive despite that they are genetically susceptible to the drug (Figure 3B). The drug concentration is adequately high for a sufficiently long time, however, to eliminate the small subpopulation of partially resistant cells. If the probability of a large mutation for resistance is low $\left(\mu_{\mathrm{L}}=10^{-10}\right)$, then highly resistant cells (with $r=3$ ) are not predicted to appear until the burst of population growth that occurs when the drug application is finished. If another dose of the drug is applied again later, it will have little effect on the growth of the tumor, already enriched with resistant cells. Alternatively, if large mutations are more probable $\left(\mu_{\mathrm{L}}=10^{-6}\right)$ then fully resistant cells are predicted to evolve to a fairly high frequency of one in every 10,000 cells before the tumor is detected.

At the other extreme, the same cumulative amount of a CS drug as used in Figure 3B may be applied at too slow a rate if $\mathrm{CI}$ is too prolonged (Figure $3 \mathrm{C}$ ). In this case, although all susceptible cells are killed, many of the partially resistant cells survive. Again, if $\mu_{\mathrm{L}}=10^{-6}$ then highly resistant cells reach high levels early in treatment. If $\mu_{\mathrm{L}}=10^{-10}$ they appear after 2,000 days of tumor growth, later than if the drug is given too fast as in Figure $3 \mathrm{~B}$ since the tumor contains fewer cells, and thus fewer opportunities, for mutations conferring high resistance.

Finally, when the CS drug is infused at a rate intermediate between that pictured in Figures $3 \mathrm{~B}-\mathrm{C}$, calculations indicate that the tumor may be killed before clones with substantial levels of resistance appear, provided $\mu_{\mathrm{L}}=10^{-10}$ (Figure 3D). The total time of treatment is long; since $52.5 \%$ of cells are in the G0 state when treatment commences, to reach 
A

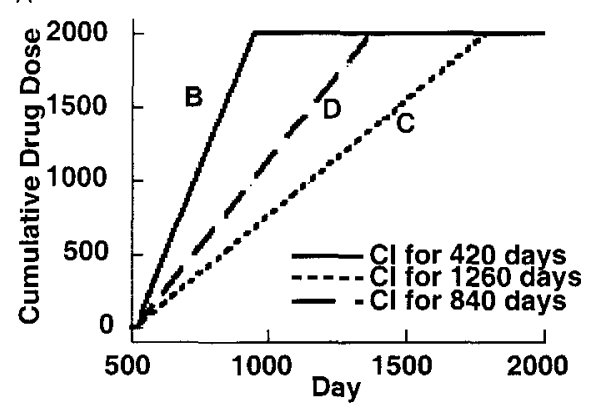

C

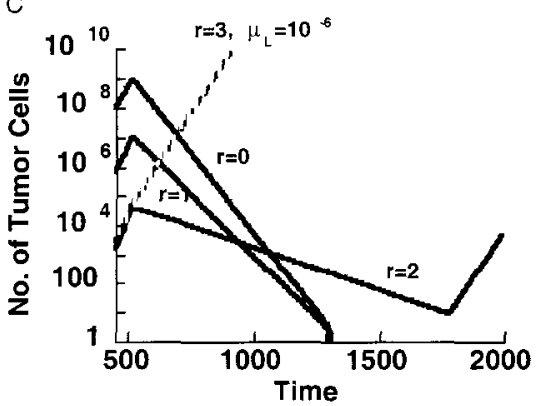

B

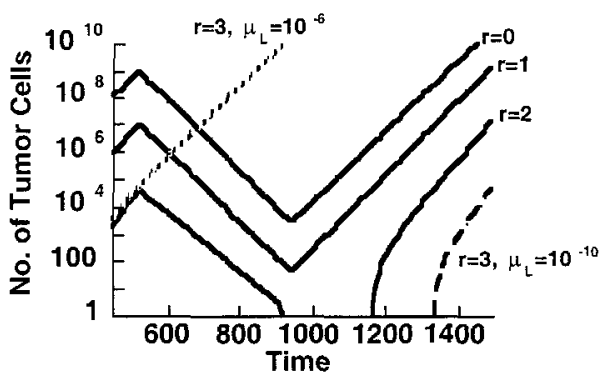

D

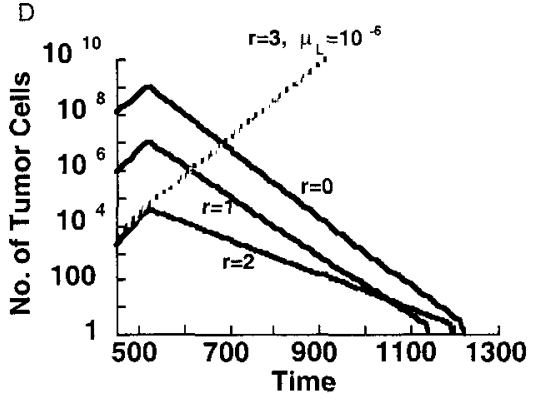

FIGURE 3 A) Cumulative drug dose versus time for parts B), C), and D), with curves labeled as such. B-D) The number of cells in each susceptible $(r=0)$, partially $(r=1$ or 2$)$, or fully resistant $(r=3)$ subpopulation in the tumor versus time in days, when a CS drug is applied. Tumor growth starts at $t=0$ days, and the tumor is detected after approximately 500 days of growth. In B) the CS drug is applied too quickly, and the susceptible population survives chemotherapy $(u=14$ days, $z=30$ fractions, i.e. continuous infusion for 420 days). In C) drug application is too slow, and partially resistant cells survive $(u=14$ days, $z=90$ fractions, i.e. continuous infusion for 1260 days). In D) the rate of drug application and the duration of chemotherapy is intermediate between those in parts $\mathrm{B}$ and $\mathrm{C}$, and cure is predicted if $\mu_{\mathrm{L}}$ is small ( $u=14$ days, $z=60$ fractions). The dashed line represents the subpopulation with $r=3$ if $\mu_{\mathrm{L}}=10^{-10}$, and the dotted line if $\mu_{\mathrm{L}}=10^{6}$. Cure is predicted only if $\mu_{\mathrm{L}}=10^{-10}$, since if $\mu_{\mathrm{L}}=10^{-6}$ fully resistant cells make up a considerable proportion of the tumor even before chemotherapy is started. $D=2000 \mathrm{mg} \mathrm{m} 2$.

all cells with the CS drug requires many months for them to enter the proliferating state.

Calculations using a CNS drug generate similar results to those for the CS drug (Figure 4). The drug may be given too quickly since it takes some time to reduce the tumor down to one cell, and during that time a sufficiently high dose must be maintained for mortality to overcompensate division (Figure 4B). As with the CS drug, administering the drug too slowly allows partially resistant cells to survive (Figure 4C). Some intermediate rate of giving the drug is predicted to be most likely to cure the tumor (Figure 4D).

Comparing Figures 3 and 4 suggest that a CNS drug may be given at a higher concentration for a shorter duration than a CS drug. One might increase the duration of drug exposure to a given, cumulative amount of drug either by prolonging $\mathrm{CI}$ at each fraction, or by dividing the dose into more fractions. Plotting the contours of the predicted time to patient death versus the number of fractions and the duration of $\mathrm{CI}$ at each fraction shows the schedule combinations likely to maximize survival time. For a CS drug, schedule combinations with $60-100$ fractions each given by $\mathrm{CI}$ for $7-14$ days are predicted to maximize the time to patient death (Figure 5A). For a CNS drug, dividing the total dose into only 4-8 fractions is predicted to lead to the longest survival of the host. As with a CS drug, prolonged CI for 10-14 days at each fraction is predicted to give the best prognosis for cure. With a CNS drug, dividing the dose into too few fractions is predicted to be more detrimental to the patient than dividing the dose into too many fractions. Contour plots of the nadir of tumor size show a similar pattern, with tumor cure predicted at some intermediate 

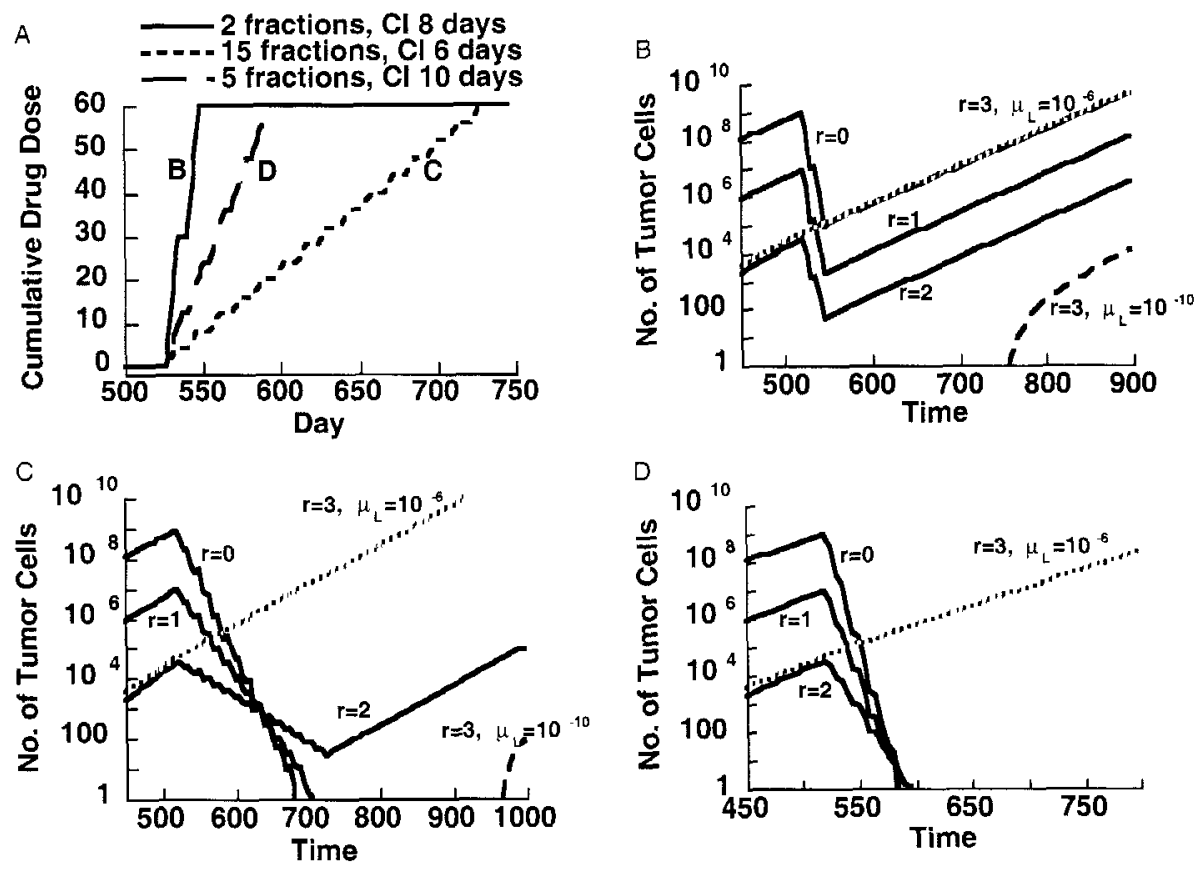

FIGURE 4 As in Figure 3, using a CNS drug. A) Cumulative drug dose versus time. In B) the drug is given too quickly $(u=8$ days, $z=2$ fractions). In $\mathrm{C}$ ), the drug is given too slowly ( $u=6$ days, $z=15$ fractions). In $\mathrm{D})$ the schedule is just right $(u=10$ days, $z=5$ fractions). $D=60 \mathrm{mg} \mathrm{m}^{-2}$.

number of fractions and prolonged $\mathrm{Cl}$ at each fraction (Figure 5C-D).

Results of sensitivity analyses varying the transition rates $m$ or $v$ as specified in the methods predict that these transition rates have only minor effects on the schedule combinations (the number of fractions and the duration of $\mathrm{CI}$ ) that minimize tumor size. The actual value of the minimum tumor size, however, depends on the values of the transition rates, as these rates affect the fraction of proliferating cells and the level of de novo resistance in the tumor. For example, increasing $m$ or $v$ results in a higher growth fraction, the effect of which will be discussed shortly. If the transition rate $g_{0}$ is twice that of the baseline value or $b$ is a low 0.2 , however, the model leads to predictions that the tumor may be cured with a CNS drug if it is applied in at least 6 fractions each given for a duration of at least 6 days (Figure 6). Using a CS drug on tumors with high $g_{0}$ or low $b$ is not predicted to achieve cure, and the drug must be split into more fractions to obtain the minimum tumor size than in a tumor with the baseline values of $g_{0}$ and $b$.

\section{Cumulative Dose}

Contour plots of the minimum tumor size versus the cumulative dose $D$ and the duration of $\mathrm{CI}$ (applied continuously with no breaks between fractions) suggest that the duration of chemotherapy with a CS drug (Figure 7A) may have a greater impact on minimizing tumor size than the cumulative dose; when chemotherapy continues for only 150 days, any doses above $100 \mathrm{mg} \mathrm{m}^{-2}$ are not predicted to reduce tumor size by more than one order of magnitude. Although this is a clinically substantial reduction, it comes nowhere close to cure. High cumulative doses applied over 700 days, however, are predicted to reduce tumor size down to less than 10 cells.

The cumulative dose is predicted to be more important for a CNS drug than for a CS drug, provided chemotherapy is given for at least 40 days 

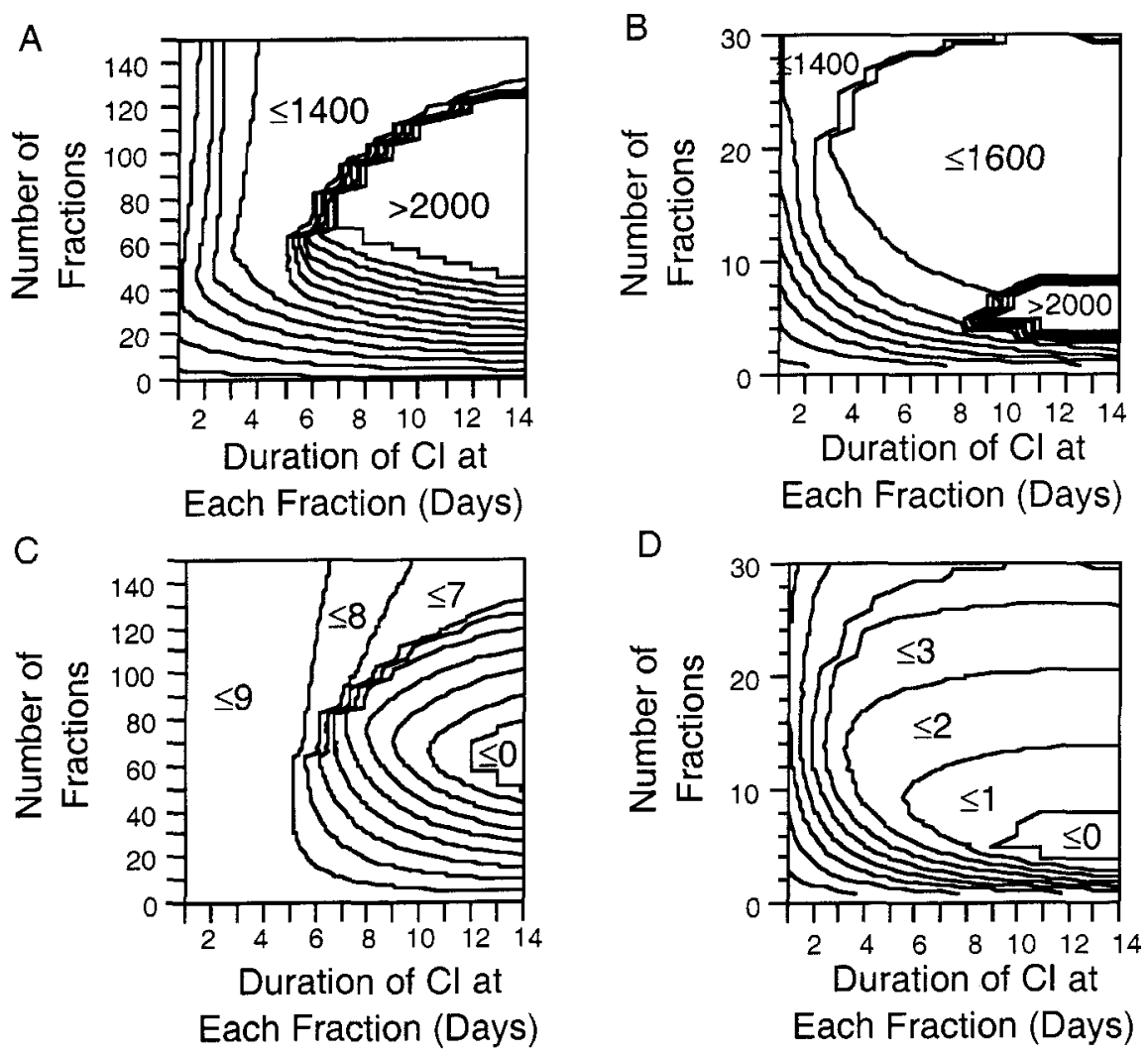

Each Fraction (Days)

FIGURE 5 A-B) Contour plots of the time to host death from tumor inception versus the number of fractions z into which the cumulative dose is divided and the duration of $\mathrm{Cl}$ at each fraction. Parts $\mathrm{C}$ ) and D) plot the contours of the $\log _{10}$ (minimum tumor size +1 ). Contour lines are plotted for every one $\log _{10}$ of tumor size or 100 days of host survival. A) and C) illustrate results using a CS drug, and B) and D) represent results from applying a CNS drug. Long durations of CI at each fraction are predicted to result in the longest host survival and minimum tumor size. 60-80 fractions are predicted to result in tumor cure for the CS drug, while 4-8 fractions are predicted to eradicate the tumor using a CNS drug. Parameter values used here and in the following figures unless specified otherwise are $\mu_{\mathrm{L}}=10^{-10}, D=2000 \mathrm{mg} \mathrm{m}^{-2}$ for the CS drug, and $D=60 \mathrm{mg} \mathrm{m}^{-2}$ for the CNS drug.

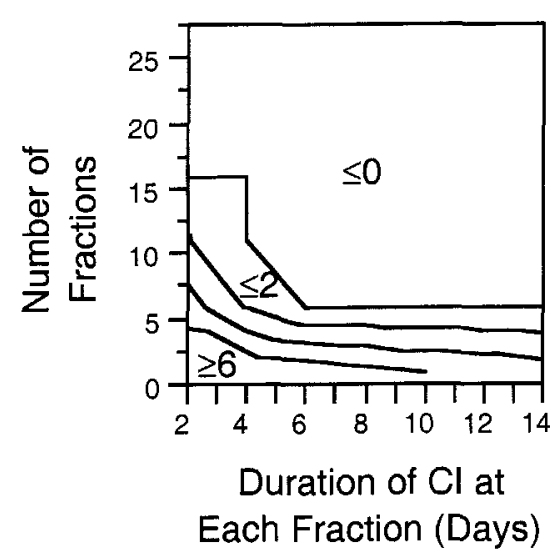

FIGURE 6 The contours of the $\log _{10}$ (minimum tumor size+1) as in Figure 5D) using a CNS drug applied to a tumor with $g_{0}=0.2$. A plot of the same result for a tumor with $b=0.2$ looks similar.
(Figure 7B). Similar patterns occur for the time to host death (Figure 7C,D).

\section{Cell Cycle Time and Proliferative Fraction}

The cell division rate $b \quad(b=\log (2) /$ time of cell cycle) influences the predicted outcome of chemotherapy differently for a CNS than for a CS drug (Figure 8A,B). The model calculates that a CNS drug may eradicate a tumor if $b \leq 0.5$, that is, the cell cycle takes at least 33 hours to complete. In comparison, if the cell division rate is slower than in typical human tumors $(b \leq 0.3$, i.e., the cell cycle takes $2-4$ days to complete, Steel 1977) then the model predicts that the tumor may not 
A

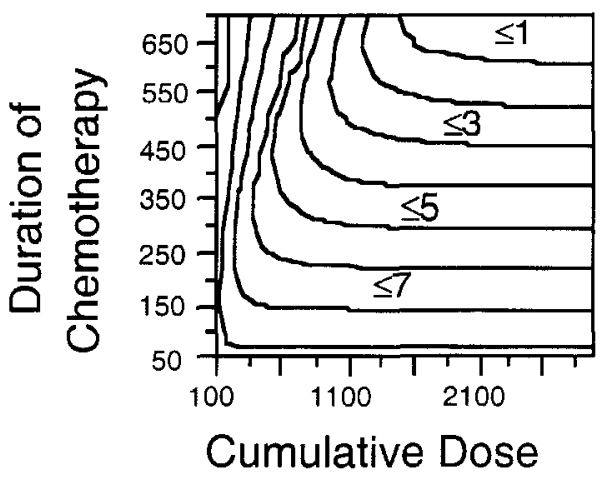

C

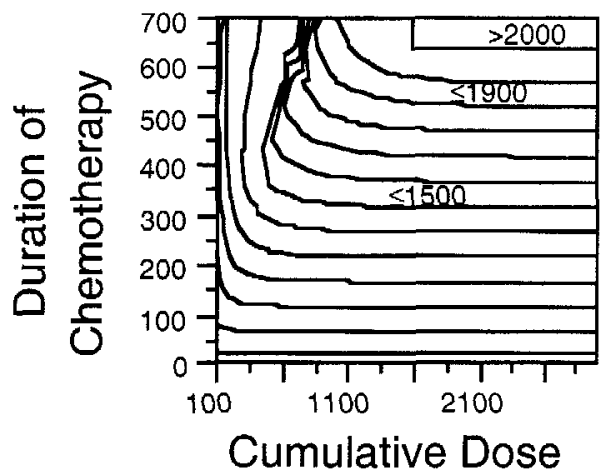

B

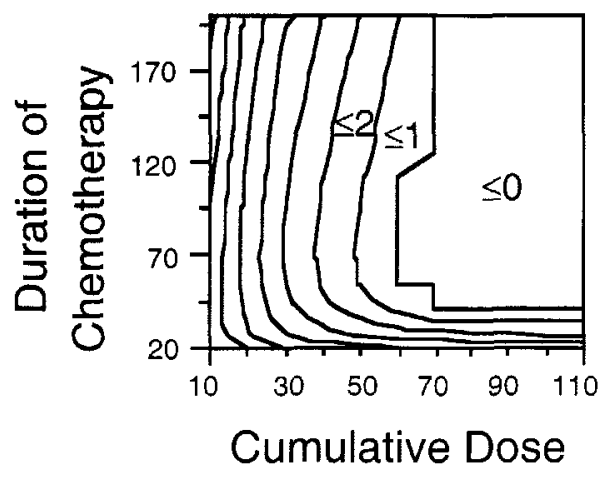

D

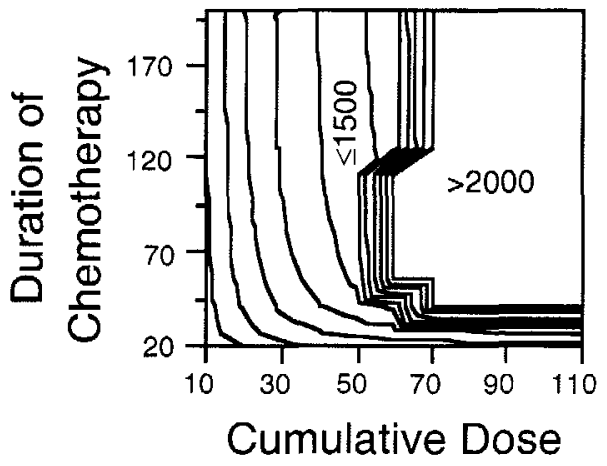

FIGURE 7 Contours of $A$ ) and $B$ ) the $\log _{10}$ (minimum tumor size +1 ), and $C$ ) and D) host lifespan following tumor inception versus the duration of chemotherapy (in days) and the cumulative dose $D \mathrm{mg} \mathrm{m}{ }^{2}$. Chemotherapy is give by continuous infusion for the entire duration of treatment. In A) and C) the CS drug is used, and in B) and D) the CNS drug is applied. The duration of chemotherapy is more important in the success of treatment with a CS drug. given that a minimim threshold dose is applied. In contrast, the cumulative dose plays a larger role for treatment with a CNS drug, given that a minimum threshold duration of drug exposure is achieved.

be cured using a CS drug, but the time to host death will be long (about 10 years). For moderate cell division rates in which $0.4 \leq b \leq 0.5$ (the cell cycle takes 33-42 hours), results indicate that it may be possible to cure the tumor using a CS drug given an adequate dose and duration of exposure. Calculations suggest that when the cell division rate is higher than in typical human tumors $(b \geq 0.6$, cell cycle time is less than 28 hours, Steel 1977), neither a CS nor a CNS drug may be successful in eradicating the tumor, although a CS drug may prolong the host's lifespan up to 2 months longer than could the CNS drug (Figure 8C). In summary, a CNS drug is predicted to be more successful at treating tumors with slow rates of cell division, and may result in cure, while a CS drug is predicted to be more successful in extending the host's lifespan for tumors with a fast rate of cell division.

The fraction of proliferating cells has a similar effect on the minimum tumor size and the time to host death to that of the cell cycle time. As the transition rate $g_{0}$ to the resting state increases, the fraction of proliferating cells declines (Figure 9A). CS drugs (Figure 9B) are predicted to be able to eradicate tumors with higher proliferative (growth) fractions than are CNS drugs (i.e., for $g_{0}=0.1$ ), while CNS drugs are predicted to be more effective against tumors with a low proliferative fraction $\left(g_{0}>0.18\right.$, Figure 9C). When the growth fraction is very low, less than $20 \%$, highly resistant cells are predicted to appear through gene amplification $\left(\mu_{\mathrm{S}}\right)$ even before chemotherapy begins, and even when 

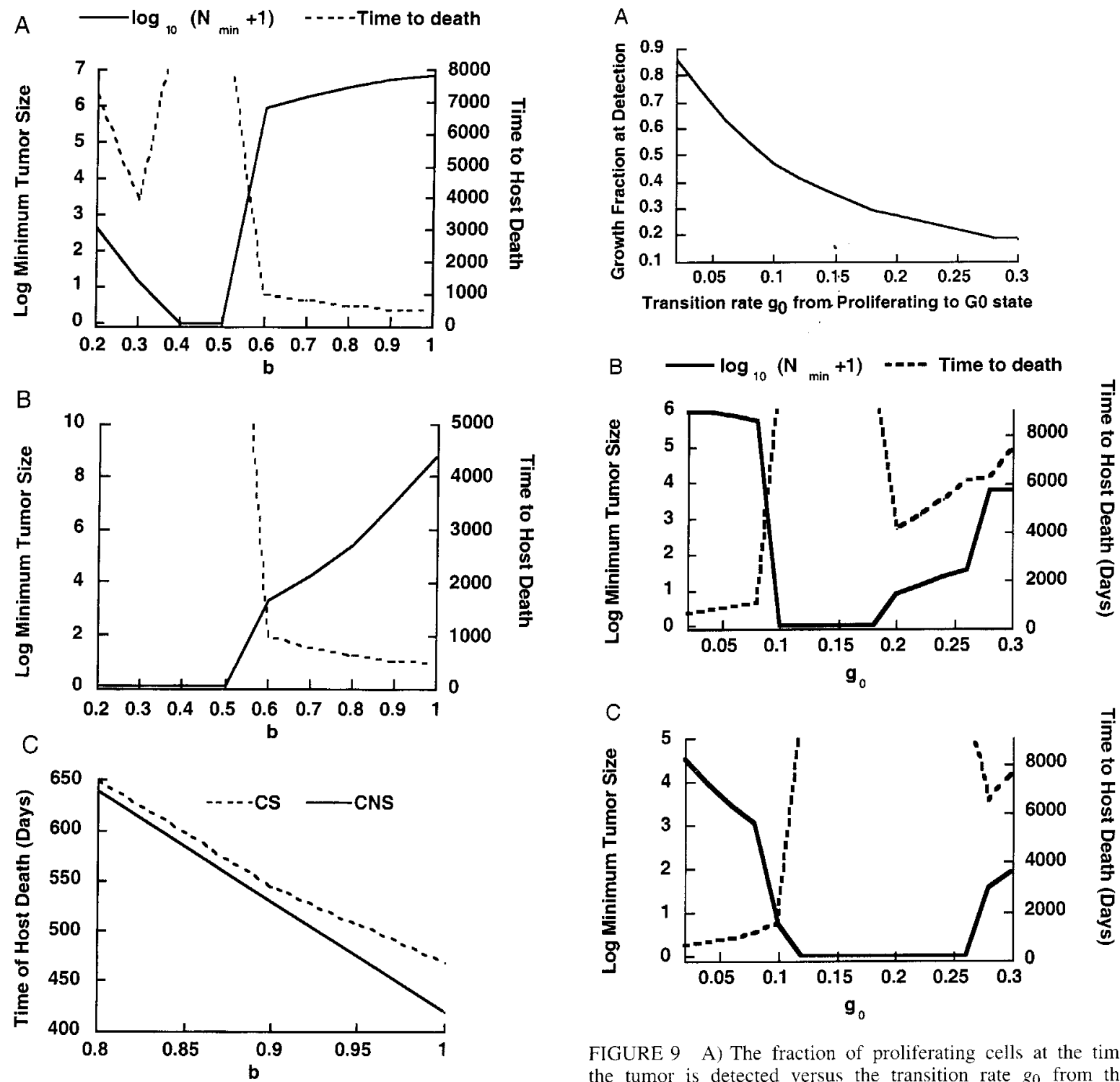

FIGURE 9 A) The fraction of proliferating cells at the time the tumor is detected versus the transition rate $g_{0}$ from the proliferating to the resting state. $\mathrm{B}$ ) and $\mathrm{C}$ ) The minimum tumor size and time to host death, as in Figure 8A and B, versus $g_{0}$ for B) CS and C) CNS drugs. CS drugs are predicted to achieve cure for slightly lower values of $g_{0}\left(g_{0}=0.1\right)$ than are CNS drugs, but the time to host death for lower values of $g_{0}$ are predicted to be the same whether the drug is CS or CNS. CNS drugs are predicted to result in a better prognosis when $g_{0}$ is above 0.18 .

high levels of resistance through gene amplification in tumors with low growth fractions occurs since the few proliferating cells must go through many rounds of cell division before the tumor reaches a detectable size. This provides more opportunities for proliferating cells to accumulate stepwise mutations fail for tumors with very low growth fractions when they are treated with a CNS drug. The evolution of 
than in tumors with a higher growth fraction. In summary, tumors with either very low or very high proliferative fractions are not predicted to be cured by either CS or CNS drugs. Results suggest that only tumors with moderate proliferative fractions, between $25-45 \%$ of cells, may be curable with a single CS or CNS drug.

\section{DISCUSSION AND CONCLUSIONS}

The models lead to predictions that a CS drug may be applied most effectively by long-term chemotherapy, splitting the cumulative dose into at least 40 fractions in order to expose all cells to the drug as they move from the resting to the proliferating state, but not more than 80 fractions so as to maintain sufficient drug concentrations to kill sightly resistant cells. In contrast, CNS drugs are predicted to be more effectively applied in five to ten fractions applied over a shorter term. The model suggests that administering each fraction by continuous infusion for more than 11 days may be more effective than giving the drug as a bolus, for both CS and CNS drugs. The reasoning is that maintaining moderately high doses for more than a week prevents tumor regrowth between fractions, particularly of partially resistant cells. It takes some time for cell death to overwhelm proliferation of surviving cells, and during that time a sufficiently high drug concentration to cause cell death must be maintained by continuous infusion. Finally, tumors with a low growth fraction or slow rate of cell division are predicted to be controlled more easily with CNS drugs since they can kill cells which are not dividing. In contrast, tumors with a high proliferative fraction or fast cell division rate may respond better to $\mathrm{CS}$ drugs, since CS drugs preferentially kill the dividing cells which might otherwise give rise to resistant offspring.

The model predicts that prolonged exposure to a CS drug may be more important in extending patient life and minimizing tumor size than using high doses. Dividing the total dose into a number of fractions and applying each fraction by continuous infusion for many days is predicted to yield the most promising results for the patient, although it may be possible to divide the dose into so many fractions of low concentration that resistance evolution is facilitated. A number of in vivo studies have found improved success of $\mathrm{CI}$ relative to bolus treatment using CS drugs (Toussaint et al. 1994, Leichman et al. 1995, Fulton et al. 1996, Wolmark et al. 1998). The theoretical predictions about dose response of a CS drug may help explain why Mackean et al. (1998) found no significant difference in outcome between low and high dose 5fluorouracil applied for the same duration at each dose level.

In contrast, for CNS drugs, augmenting the dose is predicted to elicit a greater improvement in cell kill than is possible from extending the duration of exposure. Indeed, in clinical trials high dose regimens using CNS drugs resulted in improved disease-free survival (Livingston 1994). Model results suggest that treatment with a CNS drug should be divided into fewer fractions of higher concentration compared with the treatment schedule of a CS drug, in support of the original hypothesis that a CNS drug should be given more quickly than a CS drug. Applying each dose fraction as a long duration CI is also predicted to be effective in minimizing tumor size and maximizing host lifespan. This result contradicted the original hypothesis that bolus application of a CNS drug might be better than $\mathrm{CI}$, and occurs since regrowth between dose spikes partially counteracts the tumor reduction achieved while the drug is at a high concentration. Empirical results using cell cycle non-specific antitumor antibiotics and alkylating agents support this prediction (McArthur et al. 1970, Farhangi and Osserman 1973, Sikic et al. 1978, Pacciarini et al. 1978, Skubitz et al. 1993, Campisi et al. 1998). However, literature surveys indicate that fewer clinical studies have compared CI versus bolus application of CNS drugs than of CS drugs.

Swan and Vincent (1977) and Swan (1990) used optimal control theory to model tumor reduction for CNS drugs. Although they did not incorporate resistance evolution, they also concluded that $\mathrm{CI}$ is 
superior to discrete dosage regimens. Murray (1995) also modeled tumor control and resistance evolution for a CNS drug, and predicted that a combination of one or two dose spikes with an intervening period of CI minimizes tumor size.

As illustrated in Figures 3-4, if cells which are fully resistant to high drug concentrations can evolve in a single step, then with $\mu_{\mathrm{L}}$ as high as $10^{-6}$ cure may be impossible with a single drug. Highly resistant cells are likely to be present even before drug exposure occurs, and low drug concentrations will not facilitate the evolution of resistance any more than high concentrations. With many drugs, however, resistance in the clinical setting has been shown to evolve by gene amplification (Horns et al. 1984, Curt et al. 1983, Trent et al. 1984, Cardman et al. 1984, Kellen 1994, Bodey et al. 1997), and in these situations the double bind described here may apply.

As mentioned in the introduction, tumor cell kill must be balanced with toxicity to the host. In clinical trials of a number of drugs and types of cancer, $\mathrm{CI}$ is less toxic than bolus treatments (Bleyer et al. 1978, Antman et al. 1989, Anderson et al. 1991, Zalupski et al. 1991, Wolmark et al. 1998). Some theoretical studies and experiments on animal models, however, suggest that CI may be more toxic to the host, since dividing host cells, as well as tumor cells, are also killed in higher numbers (Skipper et al. 1967, Ubezio et al. 1992, Agur 1998). Cojocaru and Agur (1992) developed a model leading to predictions that spiked doses separated by an interval that is an integer multiple of the host cell-cycle time can minimize host toxicity, while "pathogen elimination may not necessarily be hampered" (p.94), called the Z-method (Agur 1998). Clinical trials have not applied bolus treatments using the Z-method, so it is unclear whether CI or bolus following the Z-method would be less toxic.

It has been suggested that increasing the proliferative fraction may render more cells susceptible to CS drugs and, consequently, improve cure rates (Simpson-Herren and Lloyd 1970, Kimler et al. 1983, Paridaens et al. 1993, Fabian et al. 1994). Such attempts, however, have not succeeded.
Paridaens et al. (1993) and Fabian et al. (1994) administered estrogen before chemotherapy with CS and CNS drugs to breast cancer patients. Although hormonal treatment recruited more cells into division, they observed no difference in response rates or survival from controls in which chemotherapy was given without estrogenic recruitment. In other trials using hormonal recruitment, dangerous flares in tumor growth occurred (Suarez et al. 1982, Manni et al. 1987, Manni et al. 1988), and in one study a survival disadvantage was reported (Manni et al. 1988). In other studies also, high curability does not always correlate with a high growth fraction (Goldie and Coldman 1984). Indeed, the model presented here leads to predictions that tumors with high proliferative fractions are unlikely to be cured by either CS or CNS drugs, and that they grow to lethal sizes more quickly than tumors with lower proliferative fractions.

In conclusion, this model leads to predictions that CI of both CS and CNS drugs may minimize tumor size and maximize the survival of the host. Results suggest that a CS drug should be applied as a large number of fractions over a long period of time, while CNS drugs may be better applied in fewer fractions. Dividing the drug into too many fractions may be counterproductive, since partially resistant cells may survive and mutate to higher levels of resistance. CS drugs are predicted to be more successful than CNS drugs for tumors with high proliferative fractions or fast rates of cell division, while CNS drugs may be more effective against tumors with the opposite conditions.

\section{Acknowledgments}

Comments from C. Godfray, J. Gressel, B. Jones, J. Sherratt, D. Vigushin, and three anonymous reviewers improved previous drafts of the paper. This work was supported by NERC core funding to the Centre for Population Biology at Silwood Park and partially by the US Department of Energy through Lawrence Livermore National Laboratory under contract No. W7405-ENG-48. 


\section{References}

Agur, Z. (1998). Resonance and anti-resonance in the design of chemotherapeutic protocols. J. Theoret. Med., 1, 237-245.

Anderson, H., Prendiville, J., Thatcher, N., Radford, J. A. and Swindell, R. (1991). A randomized study of intravenous bolus versus continuous infusion of ifosfamide and doxorubicin with oral etoposide for small-cell lung cancer. Journal of Cancer Research and Clinical Oncology, 117, S139-S140.

Antman, K. H., Ryan, L., Elias, A., Sherman, D. and Grier, H. E. (1989). Response to ifosfamide and mesna: 124 previously treated patients with metastatic or unresectable sarcoma. Joumal of Clinical Oncology, 7, 126-131.

Bezwoda, W, R., Seymour, L. and Darsey, R. D. (1995). Highdose chemotherapy with hematopoietic rescue as primary treatment for metastic breast cancer: a randomized trial. Journal of Clinical Oncology, 13, 2483-2489.

Birkhead, B. G., Rankin, E. M., Gallivan, S., Dones, L. and Rubens, R. D. (1987). A mathematical model of the development of drug resistance to cancer chemotherapy. European Joumal of Cancer Clinical Oncology, 23, $1421-1427$.

Bleyer, W. A., Poplack, D. G. and Simon, R. M. (1978). "Concentration $x$ time" methotrexate via a subcutaneous reservoir: a less toxic regimen for intraventricular chemotherapy of central nervous system neoplasms. Blood, 51, 835-842.

Bodey, B., Bodey, B. Jr., Groger, A. M., Luck, J, V.. Siegel, S. E., Taylor, C. R. and Kaiser, H. E. (1997). Immunocytochemical detection of the p170 multidrug resistance (MDR) and the p53 tumor suppressor gene proteins in human breast cancer cells: clinical and therapeutical significance. Anticancer Research, 17, 1311-1318.

Bruce, W. R., Mecker, R. E. and Valeriote, F. A. (1966). Comparison of the sensitivity of normal hematopoietic and transplanted lymphoma colony-forming cells to chemotherapeutic agents administered in vivo. Journal of the National Cancer lnstitute, 37, 233-245.

Campisi, C., Fabi, A.. Papaldo, P., Tomao, S., Massidda, B. Zappala, A., Ionta, M. T. and Cognetti, F. (1998). Ifosfamide given by continuous-intravenous infusion in association with vinorelbine in patients with anthracycline-resistant metastatic breast cancer: A phase I-II clinical trial. Annals of Oncology, 9. 565-567.

Canal, P., Gay, C., Dezeuze, A., Douillard, J. Y., Bugat, R., Brunet, R., Adenis, A., Herait, P., Lokiec, F. and MathieuBoue, A. (1996). Pharmacokinetics and pharmacodynamics of irinotecan during a Phase II clinical trial in colorectal cancer. Pharmacology and Molecular Mechanisms Group of the European Organization for Research and Treatment of Cancer. Journal of the National Cancer Institute (Bethesda), 14, 2688-2695.

Cardman, M. D., Schornagel, J. H., Rivest, R. S., Srimatkandada, S., Portlock, C. S., Duffy, T. and Bertino, J. R. (1984). Resistance to methotrexate due to gene amplification in a patient with acute leukemia. Journal of Clinical Oncology, 2, $16-20$.

Cojocaru, L. and Agur, Z. (1992). A theoretical analysis of interval drug dosing for cell-cycle-phase-specific drugs. Mathematical Biosciences, 109, 85-97.

Coldman, A. J. and Goldie, J. H. (1987a). Impact of doseintense chemotherapy on the development of permanent drug resistance. Seminars in Oncology, 14, 29-33.

Coldman, A. J. and Goldie, J. H. (1987b). Modeling resistance to cancer chemotherapeutic agents. In J. R. Thompson and B. W. Brown (eds.), Cancer Modelling. pp. 315-364. New York: Marcel Dekker.
Comandone, A., Leone, L., Oliva, C., Frustaci, S. Monteleone, M., Colussi, A. M., DalCanton. O., Bergnolo, P., Boglione, A. and Bumma, C. (1998). Pharmacokinetics of ifosfamide administered according to three different schedules in metastatic soft tissue and bone sarcomas. Joumal of Chemotherapy, 10, 385-393.

Curt, G. A., Carney, D. M., Cowan, K. H., Jolivet, J., Bailey, B. D., Drake, J. C., Kao-Shan, C. W., Minna, J. D. and Chabner, B. A. (1983). Unstable methotrexate resistance in human small-cell carcinoma associated with double minute chromosomes. New England Journal of Medicine, 308, 199-202.

Devonshire, A. L. and Field, L. M. (1991). Gene amplification and insecticide resistance. Annual Review of Entomology, 36, $1-23$.

Donehower, R. C. (1990). Evaluating cancer chemotherapy by infusion. Journal of the National Cancer Institute, 82, $1867-1868$.

Duk, H. N. and Nickolls, P. M. (1987). Multicompartment models of cancer chemotherapy incorporating resistant cell populations. Journal of Phamacokinetics and Biopharmacology, 2 , $145-177$.

Eichholtz, H. and Trott, K. R. (1980). Effect of methotrexate concentration and exposure time on mammalian cell survival in vitro. British Journal of Cancer, 41, 277-284.

Evans, W. E. (1988). Clinical pharmacodynamics of anticancer drugs: a basis for extending the concept of dose-intensity. Blat, 56, $241-248$.

Fabian, C. J., Kimler, B. F., McKittrick, R., Park, C. H., Lin, F., Krishnan, L., Jewell, W. R.. Osborne, C. K.. Martino, S., Hutchins, L. F., Leong, L. A. and Green, S. (1994). Recruitment with high physiological doses of estradiol preceding chemotherapy: flow cytometric and therapeutic results in women with locally advanced breast cancer - a Southwest Oncology Group Study. Cancer Research, 54, 5357-5362.

Farhangi, M. and Osserman, E. F. (1973). The treatment of multiple myeloma. Seminars in Hematology, 10, 149-161.

Frei, M. III. and Canellos, G. P. (1980). Dose: a critical factor in cancer chemotherapy. American Journal of Medicine, 69 , $585-594$.

Fulton, D., Urtasun, R. and Forsyth, P. (1996). Phase-II study of prolonged oral-therapy with etoposide (VP16) for patients with recurrent malignant glioma. Journal of Clinical Oncology, 27. $149-155$.

Gasparini, G., Pozza, F., Meli, S., Reitano, M., Santini, G. and Bevilacqua, P. (1991). Breast cancer cell kinetics: immunocytochemical determination of growth fractions by monoclonal antibody Ki-67 and correlation with flow cytometric S-phase and with some features of tumor aggressiveness. Anticancer Research, 11, 2015-2022.

Gardner, S. N., Gressel, J. and Mangel, M. (1998). A revolving dose strategy to delay the evolution of both quantitative vs major monogene resistances to pesticides and drugs. International Journal of Pest Management, 44, 161-180.

Goldie, J.H. and Coldman, A.J. (1998). The biological basis of cancer and the problem of drug resistance. In Drug Resistance in Cancer, Mechanisms and Models. pp. 1-23. Cambridge: Cambridge University Press.

Goldie, J. H. and Coldman, A. J. (1984). The genetic origin of drug resistance in neoplasms: Implications for system therapy. Cancer Research, 44, 3643-3653.

Gressel, J., Gardner, S. N. and Mangel, M. (1996). Prevention Versus Remediation in Resistance Management. In T. M. Brown (ed.), Molecular Genetics and Evolution of Pesticide Resistance. pp. 169-186. Washington, D.C.: American Chemical Society. 
Griswold, D. P., Trader, M. W., Frei, E. III., Peters, W. P. Wolpert, M. K. and Laster, W. R. Jr. (1987). Response of drug-sensitive and -resistant L1210 leukemias to high-dose chemotherapy. Cancer Research, 47, 2323-2327.

Gyllenberg, M. and Webb, G. F. (1989). Quiescence as an explanation of Gompertzian tumor growth. Growth, Development \& Aging, 53, 25-33.

Harnevo, L.E. and Agur, Z. (1991). The dynamics of gene amplification described as a multitype compartmental model and as a branching process. Mathematical Biosciences, 103, 115-138.

Harnevo, L. E. and Agur. Z. (1992). Drug resistance as a dynamic process in a model for multistep gene amplification under various levels of selection stringency. Cancer Chemotherapy and Pharmacology, 30, 469-476.

Hokanson, J. A., Brown, B. W., Thompson, J. R., Jansson, B. and Drewinko. B. (1986). Mathematical model for human myeloma relating growth kinetics and drug resistance. Cell and Tissue Kinetics, 19, 1-10.

Horns. R. C.. Dower, W. J. and Schimke, R. T. (1984). Gene amplification in a leukemic patient treated with methotrexate. Journal of Clinical Oncology, 2, 1-7.

Hryniuk, W. (1995). Will increases in dose intensity improve outcome: pro. American Journal of Medicine, 99(6A), $69 \mathrm{~S}-70 \mathrm{~S}$.

Joel, S. P., Ellis, P., O`Byrne, K., Papamichael, D., Hall, M., Penson, R. Nicholls. S., O'Donnell, C., Constantinou, A., Woodhull, J., Nicholson, M.. Smith, I., Talbot. D. and Slevin. M. (1996). Therapeutic monitoring of continuous infusion etoposide in small-cell lung cancer. Journal of Clinical Oncology, 14, 1903-1912.

Keefe, D. A. Capizzi, R. L. and Rudnick, S. A. (1982). Methotrexate cytotoxicity for L5178Y/Asn lymphoblasts: relationship of dose and duration of exposure to tumor cell viability. Cancer Research, 42, 1641-1645.

Kellen, J. A. (1994). Molecular interrelationships in multidrug resistance. Anticancer Research, 14, 433-436.

Kerbel, R. S. (1995). Impact of multicellular resistance on the survival of solid tumors, including micrometastases. Invasion Metastasis, 14, 50-60.

Kimler, B. F., Fabian, C. and Park, C. H. (1983). Stimulation of $\mathrm{ER}+$ breast cancer cells prior to administration of cell-cyclespecific chemotherapy. Cell and Tissue Kinetics, 16, 609.

Leichman, C. G., Fleming, T. R., Muggia, F. M., Tangen, C. M., Ardalan, B., Doroshow, J. H., Meyers, F. J.. Holcombe, R. F., Weiss, G. R., Mangalik, A. and Macdonald, J. S. (1995). Phase-II study of fluorouracil and its modulation in advanced colorectal-cancer - a Southwest-OncologyGroup Study. Journal of Clinical Oncology, 13, 1303-1311.

Livingston, R. B. (1994). Dose intensity and high dose therapy: Two different concepts. Cancer, 74, 1177-1183.

Mackean, M. J., Cassidy. J., Jodrell, D. I., Paul, J., Reed. N. S., Canney, P. A., Yosef, H., Habeshaw, T., Robertson, A. G., McInnes, A. and Twelves, C. J. (1998). Bolus/infusional 5fluorouracil and folinic acid. A report on two prospective, consecutive phase II studies with 5 -fluorouracil dose escalation. British Journal of Cancer, 77, 1480-1486.

Manni, A., Santen, R. J., Boucher, A. E., Lipton, A., Harvey, H., Simmonds, M., Gordon, R., Rohner, T., Drago, J., Wettlaufer, J. and Glode, L. M. (1987). Androgen depletion and repletion as a means of potentiating the effect of cytotoxic chemotherapy in advanced prostate-cancer. J. Steroid. Biochem., 27, 551-556.

Manni, A., Bartholomew, M., Caplan, R., Boucher, A., Santen, R., Lipton, A., Harvey, H., Simmonds, M., Whitehershey, D., Gordon, R., Rohner, T., Drago, J.. Wettlaufer, J. and Glode, L. (1988). Androgen priming and chemotherapy in advanced prostate cancer: Evaluation of determinants of clinical outcone. Journal of Clinical Oncology, 6, 1456-1466.

Marusic, M., Bajzer, Z., Freyer. J, P. and Vuk-Pavlovic, S. (1994). Analysis of growth of multicellular tumour spheroids by mathematical models. Cell Proliferation, 27. 73-94.

McArthur, J. R. Athens, J. W., Wintrobe, M. W. and Cartwright, G. E. (1970). Melphalan and myeloma. Experience with a low-dose continous regimen. Amals of Internal Medicine, 72, 665-670.

Meyer, J. S. (1989). Measurements of cellular proliferation and DNA in breast carcinoma, $I n$ : J. Ragaz and I. M. Ariel (eds.), High-Risk Breast Cancer. pp. 141-171. Berlin: Springer Verlag.

Michelson, S. (1993). Mathematical models for multidrug resistance and its reversal. Cytotechnology, 12, 315-324.

Murray, J. M. (1995). An example of the effects of drug resistance on the optimal schedule for a single drug in cancer chemotherapy. IMA J. Math. Appl. Med. Biol. 12, 55-69.

Norton, L. and Simon. R. (1977). Tumor size. sensitivity to therapy, and design of treatments schedules. Cancer Treatment Reports, 61, 1307-1317.

Norton, L. and Simon, R. (1986). The Norton-Simon hypothesis revisited. Cancer Treatment Reports, 70, 163-169.

Pacciarini, M. A., Barbieri, B.. Colombo, T., Massimo. B. Garattini. S. and Donelli, M. G. (1978). Distribution and antitumor activity of adriamycin given in a high-dose and a repeated low-dose schedule to mice. Cancer Treatment Reports, 62, 791-800.

Panetta, J. C. (1998). A mathematical model of drug resistance: heterogeneous tumors. Mathematical Biosciences, 147, 41-61.

Paridaens, R., Heuson, J. C., Julien. J. P., Veyret, C., Van Zyl, J.. Klijn, J. G. M., Sylvester, R. and Mignolet, F. (1993). Assessment of estrogenic recruitment before chemotherapy in advanced breast cancer: a double-blind randomized study. Journal of Clinical Oncology, 11, 1723-1728.

Rath, H., Titsy, T. and Schimke, R. T. (1984). Rapid emergence of methotrexate resistance in cultured mouse cells. Cancer Research, 44, 3303-3306.

Rushing, D. A.. Raber, S. R., Rodvold, K. A., Piscitelli. S. C.. Plank, G. S. and Tewksbury, D. A. (1994). The effects of cyclosporine on the pharmacokinetics of doxorubicin in patients with small cell lung cancer. Cancer (Phila.), $\mathbf{7 4}$, $834-841$.

Sasaki, Y., Hakusui, H., Mizuno, S., Morita, M., Miya, T., Eguchi, K., Shinkai, T., Tamura. T., Ohe, Y, and Saijo, N. (1995). A pharmacokinetic and pharmacodynamic analysis of CPT-11 and its active metabolite SN-38. Japanese Journal of Cancer Research, 86, 101-110.

Schimke, R. T. (1984). Gene amplification, drug resistance, and cancer. Cancer Research, 44, 1735-1742.

Schimke, R. T., Hill, A. and Johnston, R. N. (1985). Methotrexate resistance and gene amplification: an experimental model for the generation of cellular heterogeneity. British Journal of Cancer, 51, 459-465.

Schoenlein, P. V. (1993). Molecular cytogenetics of multiple drug resistance. Cytotechnology, 12,63-89.

Sikic, B. I., Collins, J. M. and Mimnaugh, E. G. (1978). Improved therapeutic index of bleomycin when administered by continuous infusion in mice. Cancer Treatment Reports, 62. 2011-2017.

Simpson-Herren, L. and Lloyd, H. H. (1970). Kinetic parameters and growth curves for experimental tumor systems. Cancer Chemotherapy Reports, 54, 143-174

Skipper, H. E., Schabel, F. M., Jr. and Wilcox, W. S. (1967). Experimental evaluation of potential anticancer agents. XXI, 
Scheduling or arabinosyl cytosine to take advantage of its Sphase specificity against leukemia cells. Cancer Chemotherapy Reports, 51, 125-141.

Skipper, H. E. Schabel, F. M. and Lloyd, H. H. (1979). Doseresponse and tumor cell repopulation rate in chemotherapeutic trials. Advances in Cancer Chemotherapy, 1. 205-253.

Skubitz, K. M., Hamdan, H. and Thompson, R. C. Jr. (1993). Ambulatory continuous infusion ifosfamide with oral etoposide in advanced sarcomas. Cancer, 72, 2963-2969.

Sobrero, A. F., Aschele, C. and Bertino, J. R. (1997). Fluorouracil in colorectal cancer - A tale of two drugs: Implications for biochemical modulation. Journal of Clinical Oncology, 15, 368-381.

Steel, G. G. (1977). Growth kinetics of tumours. Oxford: Clarendon Press.

Suarez, A. J., Lamm, D. L., Radwin, H. M., Sarodsy, M., Clark, G. and Osborne, C. K. (1982). Androgen priming and cyto-toxic chemotherapy in advanced prostatic cancer. Cancer Chemotherapy and Pharmacology, 8, 26I-265.

Swan, G. W. (1990). Role of optimal control theory in cancer chemotherapy. Mathematical Biosciences, 101, 237-284.

Swan, G. W. and Vincent, T. L. (1977). Optimal control analysis in the chemotherapy of $\operatorname{IgG}$ multiple myeloma. Bulletin of Mathematical Biology, 39, 317-337

Toussaint, C., Izzo, J., Spielmann, M., Merle, S., Maylevin, F.. Armand, J.P., Lacombe, D., Tursz, T., Sunderland, M. Chabot, G. G. and Cvitkovic, E. (1994). Phase I/II trial of continuous-infusion vinorelbine for advanced breast-cancer. Journal of Clinical Oncology, 12, 2102-2112.

Trent, J. M., Buck, R. N., Olson, S., Horns, R. C. Jr. and Schimke, R. T. (1984). Cytologic evidence for gene amplification in methotrexate-resistant cells obtained from a patient with ovarian adenocarcinoma. Journal of Clinical Oncology, 2, 8-15.

Tsuruo, T. and Fidler, I. J. (1981). Differences in drug sensitivity among tumor-cells from parental tumors, selected variants, and spontaneous metastases. Cancer Research, $\mathbf{4 1}$, $3058-3064$.

Ubezio, P., Tagliabue, G., Schechter, B. and Agur, Z. (1994). Increasing 1-3-D-Arabinofuranosylcytosine efficacy by scheduled dosing intervals based on direct measurements of bone marrow cell kinetics. Cancer Research, 54, 6446-6451.

vanPutten, L. M. (1974). Are cell kinetic data relevant for the design of tumour chemotherapy schedules? Cell Tissue Kinetics, 7, 493-504.

Watson, J. V. (1991). Tumour growth dynamics. British Medical Bulletin, 47, 47-63.

Wolmark, N., Piedbois, P., Rougier, P., Buyse, M., Pignon, J. P., Ryan, L., Hansen, R., Zee, B., Weinerman, B., Pater, J., Leichman, C., Macdonald, J., Benedetti, J., Lokich, J., Fryer, J., Brufman, G., Isacson, R., Laplanche, A., Levy, E., Harrington, D., McFadden, E., Ribble, A., Jacobson, R., Luboinski, M., Vaitkevicius, V., LeBourgeois, J. P., Piedbois, Y., Gauthier, E., DurandZaleski, I., Carlson, R., Rustum, Y. and Erlichman, C. (1998). Efficacy of intravenous continuous infusion of fluorouracil compared with bolus administration in advanced colorectal cancer. Journal of Clinical Oncology, 16, 301-308.

Zalupski, M., Metch, B., Balcerzak, S., Fletcher, W. A. S., Chapman, R., Bonnet, J. D., et al. (1991). Phase III comparison of doxorubicin and dacarbazine given by bolus versus infusion in patients with soft-tissue sarcomas: a Southwest Oncology Group Study. J. Natl. Cancer Inst., 83, 926-932. 


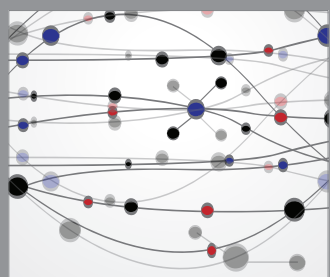

The Scientific World Journal
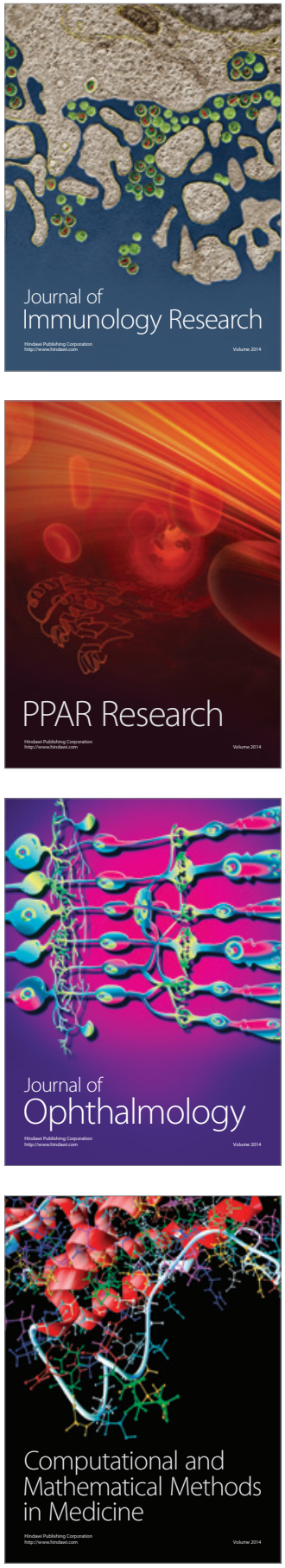

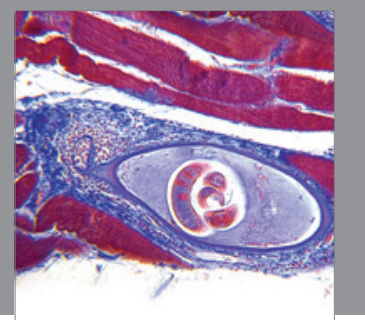

Gastroenterology

Research and Practice
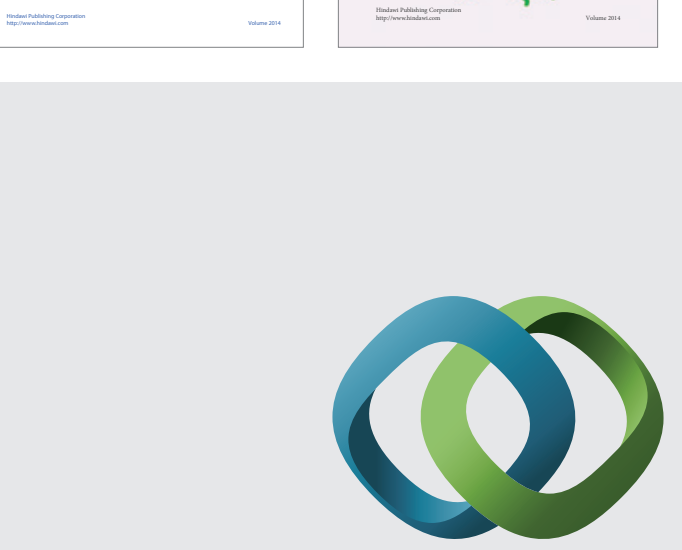

\section{Hindawi}

Submit your manuscripts at

http://www.hindawi.com
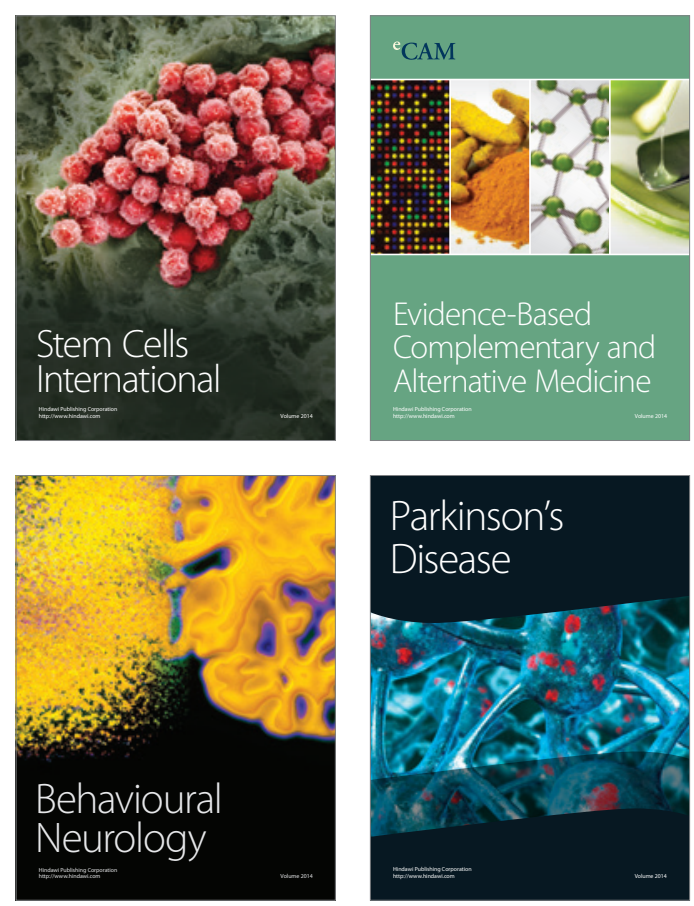

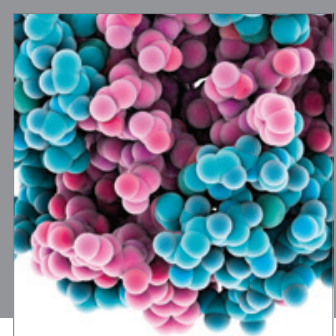

Journal of
Diabetes Research

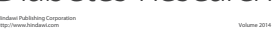

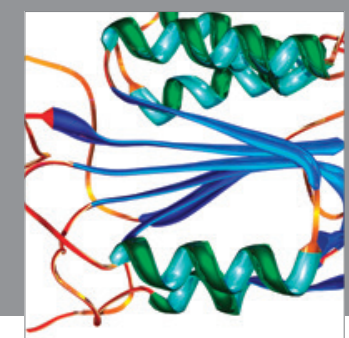

Disease Markers
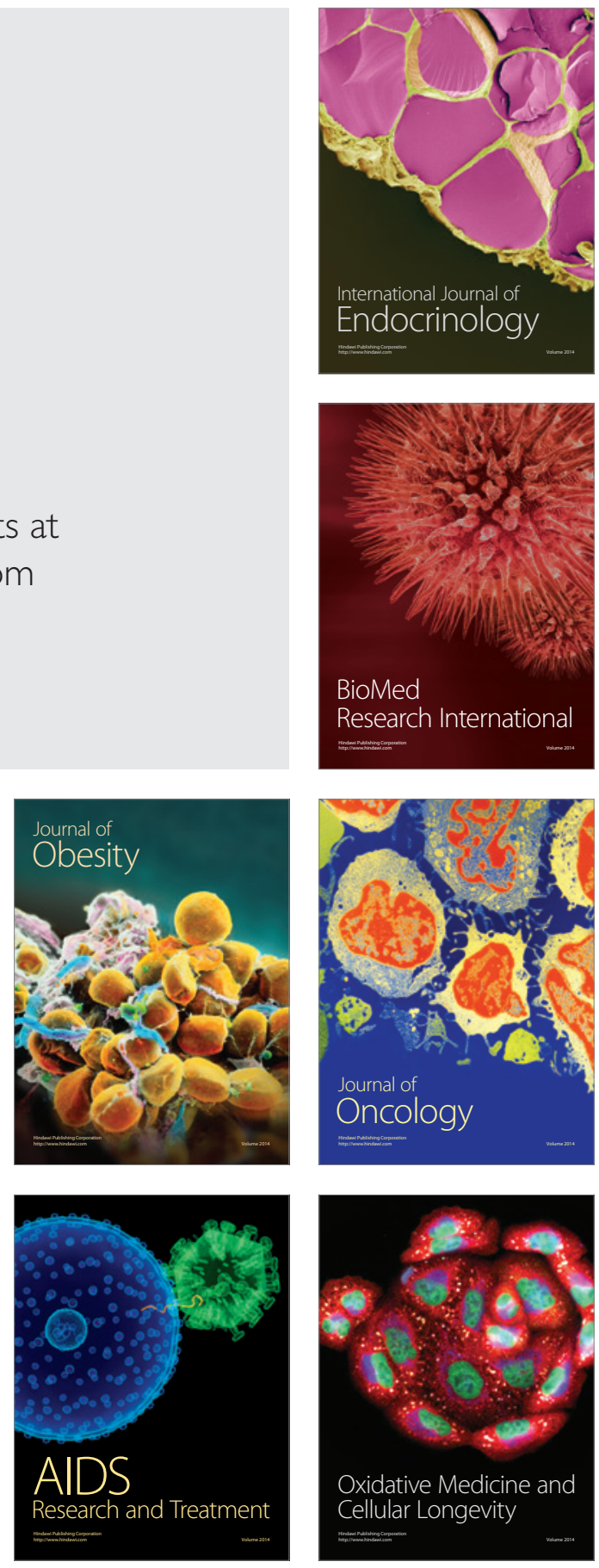